\title{
Unconventional incentive schemes in tourism enterprises, does it make sense?
}

\author{
Maciej Kozłowski ${ }^{1}$ (D) \\ Published online: 8 August 2019 \\ (C) The Author(s) 2019
}

\begin{abstract}
The purpose of this article is to describe the model of the most important employee financial participation (EFP) programs and give some proposals aiming at wider promotion of financial participation in tourist companies in order to show the occurring relations between the programs applied and the socioeconomic results of enterprises. The research has been based on available literature and own research conducted on the sample of Polish companies listed on Warsaw Stock Exchange. The author's research could serve as a guide to carry out similar research in the tourist resort. Financial participation programs existing in particular countries differ because of various circumstances in which they are applied, various range and eligibility of employees, though it is possible to find such elements which they have in common. What can be expected is a radical change in workers' attitudes towards a higher commitment, stronger identification with the company, and as a result taking responsibility for its future. It is even more important in tourist industry (in transnational tourist companies) in a comparison to the traditional one. It can be assumed that the awareness aspect plays here a vital role in the way to a success of the whole company and individual employees' as well. Unfortunately, this is not a common condition. We can expect that EFP programs generally would have a positive influence on the functioning of the tourist enterprise. However, the effects could be rather social than economic. More rigorous statistical analysis is needed to know more about economic results in tourist industry, unfortunately such studies are not conducted in tourism, so the question in the title is still open.
\end{abstract}

Keywords Financial participation · Model approach · Tourist companies · Incentive schemes $\cdot$ Recommendations

\section{Introduction}

Enterprises in the tourism industry, wanting to stay on the market and gain a competitive advantage, are increasingly faced with the need to take actions closely related to the changes in the management of these enterprises. The changes may concern not only the

Maciej Kozłowski

maciej.kozlowski@uni.lodz.pl

1 University of Lodz, Lodz, Poland 
introduction of modern forms of management, but also the change in the role of all participants towards greater decision-making participation, which in turn is associated with different forms of motivating employees than those used so far. Motivating employees is one of the main components of human resources management [apart from planning, recruitment and selection, evaluation and development of personnel (Kostera 1994)], and as it is known, individual employees are the owner of the human resource and they ultimately decide about the degree of involvement of this resource at work (Pocztowski 2003). In turn, the most important components of the human resource are: knowledge, abilities, skills, health, attitudes and values, and motivation (Leleń 2010). The comprehensive nature of the tourism product which consists of the offer of many combined services requiring cooperation of many tourism companies, not only local but also international, necessitates the development of universal and transnational activities aimed at joint management and application of similar incentive systems in different countries, but systems containing a set tools other than those used so far. It seems necessary because standard forms of motivating employees (usually payroll ${ }^{1}$ and non-payroll) have a small influence on the improvement of economic results. One should also remember about various types of cross-border barriers that hinder or even prevent wider implementation of motivational participatory solutions on a larger scale in tourist enterprises. ${ }^{2}$

The similar problems concern tourism which is related to various areas of life, which makes it an interdisciplinary phenomenon. From the economic point of view, tourism belongs to the services sector, which is the most dynamically developing sector in the economy. The contemporary tourist market is increasingly becoming a global market. Its characteristic feature is that it is dominated by large service providers, often of an international nature, which compete with each other and local and regional units. Internationalization of tourism companies' activities makes them independent of specific countries and the whole world becomes a place for them to create tourist products and market. The internationalization process also significantly changes the environment of tourism companies. Both competition and cooperation between tourist service units from different countries are intensifying, which affects the way of how human resources are managed in these enterprises, and thus requires a more modern approach to motivating employees.

\section{The European Union's proposals aiming at the wider promotion of financial participation in tourist companies}

There are several reasons for which the European Commission and the member states take now and should also take in the future strong actions leading to the liquidation of the obstacles on the way to the widespread of participation on the EU level. As first we can mention the tendency to 'europeanize' companies by establishing and developing the branches

\footnotetext{
1 In the majority of cases, the only wage tool in tourist enterprises is the basic wage, which is not satisfactory in the opinion of respondents, see Molenda (2015).

2 The barriers which hinder the introduction of transnational financial participation schemes can be classified according to several, general categories, taking into account specific conditionings which are present in the member states in the following aspects: the existing institutional structure, differences in legal, tax and insurance structures, legal regulations concerning issuing and selling bonds, labor law, regulations on financial market, social and cultural traditions in the field of application the participation schemes and the costs and complexity of the process of introduction and application of specific schemes.
} 
in the different EU countries. Recently trade and service sector are paradigmatic of these trends. The actions taken in this field in one country have indirect influence on the employees in other countries, so in this connection their range should be wider and should also take into account the economic realities of not only one country.

It should be remembered that there is an increasing need for collective managing and applying similar incentive programs within the whole EU, which in some way could exert influence on the decrease of social and cultural differences, as well as those ones in the field of managing companies, including tourist ones. In addition, the particular restrictions concerning the introduction of participation solutions in the European companies may influence the decrease their competitive position towards the firms functioning in the regions which are economically more uniform, such as the USA. Of course, the positive impact of participation on the increase of productivity, competitiveness and profitability of the European companies should not be overestimated, but the actions limiting the barriers could definitely contribute to the faster realization of the Lisbon Strategy targets. As we know, the first 4 years since its adoption in 2000 have been assessed very negatively, and as a result of this there is a more and more immediate need to take actions leading to the realization of the policy coherence strategy. The realization of this policy in the context of wider promotion of the participation solutions is conducted i.a. on the way of dialogue between the member states about the introduction of different employee profit or ownership participation schemes.

This is also underlined by ProEFP (Pro Employee Financial Participation), which is a European network promoting economic democracy in Europe and it studies, encourages all forms of employee financial participation and a larger diffusion of share/equity ownership among employees (PROEFP 4). The present new ProEFP study confirms that the European model of industrial relations is participative, yet incomplete in many countries (PROEFP 4).

The essential issue, which would improve the present situation, is a more frequent or even constant exchange of information between countries and monitoring the progress of the legislative process in every country i.a. in order to standardize legal regulations. It seems that there should be a wider analysis of the previous participation solutions, so as to choose the best possible option. The exchange of information between the employees representative on the EU level is also, which should positively influence the wider promotion of financial participation (FP). Of course such an exchange of information is functioning, yet its effects are still not satisfactory. Because of the fact that information plays a vital role in the expansion of financial participation programs, it is advisable to create a comprehensive informative network by means of the Internet, which would available to all interested parties, and most of all to transnational organs responsible for the policy on implementation of participatory solutions. Such access should also be guaranteed for other international organizations promoting these solutions. Of course, it is possible to find internet links to the websites of particular organizations and become familiar with their initiatives, yet there is probably no universal communicative network between the representatives of governments and countries who are in charge of these actions in every state. It seems that there is also a need for a much extensive analysis of the available participatory solutions in order to choose the best possible option. Highlighting the examples of financial participation programs, their implementations and achieved results would certainly accelerate the dynamics of introduction of the above-mentioned solutions, the more that there are a lot of positive solutions in literature.

An important area which needs actions to be taken on is a unification of the fiscal system, especially in the context of implementation of profit sharing or share ownership. A 
convention in this matter should include a uniform and clear interpretation of an implementation such schemes and fiscal consequences of participation in these programs in the case of companies whose headquarters are in a different country than the one which is the participant's a permanent place of residence. Social security premiums also require stable and uniform legal regulations. These would have to be clear and easy to apply regulations in the case of employees who change their place of residence and start a job in other tourist companies. It seems that such workers should still be subject to the same fiscal and social security regulations established in a country which they are leaving until the end of a particular participation program or when they decide to retire, and what is more benefits for employees from participation in a given financial scheme after changing companies should remain the same.

Therefore, it is necessary to acknowledge a program prepared within the legislative framework of one member state by the other member state, as a program which is equal to the one existing in the legislation of the other state, while at the same time maintaining identical benefits for the employee. Such cooperation would definitely be easier if there was a special directive allowing for an easy transfer of people involved in collective administering the funds gained from financial participation. A UCITS-type (Undertakings for Collective Investment in Transferable Securities) directive concerning investment funds guarantees such an easy transfer only to companies undertaking collective investments with a limited risk, which are commonly available. These funds make use of the so-called single passport rule, which means that obtaining permit in one member state gives access to markets of other EU countries. These requirements are not always met by enterprises administering the funds possessed from financial participation. Such a form of a mutual acknowledgement requires significant cooperation between member states. Similar collaboration already exists with reference to pension payments. A mutual acceptance would probably be the best option in those member states which have already gained substantial experience in the field of financial participation (France), and in this way they could encourage other states by making attempts to reduce the existing barriers between them, applying the procedure of a mutual acknowledgement. Moreover, in the long run, this procedure should lead to a gradual harmonization of the national legislation.

It seems necessary that in the future a model of European financial participation program in whole tourist branch should be developed. ${ }^{3}$ This model would serve as a means of eradicating the existing barriers and also to promote cross-border financial participation. In the first place the model would have to be accepted by every member state with reference to a national fiscal system and social security system, just like the statute of a European company. ${ }^{4}$ Another step toward broader coordination should be incorporating into the model ascertain fundamental legislation on taxation and social security. This would provide an answer to the question of whether an increase in incomes in a member state ought to be treated as a revenue from the fact of being employed and the employment relationship, or maybe as a revenue from money capitals, and would also specify the time of obtaining an income. The fact of leaving freedom to member states on granting special fiscal or social

\footnotetext{
3 So far the main focus in services has been on facility management, catering and hospitality industry.

4 A legal framework for the establishment and regulation of European company's statute is contained in Council Regulation (EC) no. 2157/2001 of October 8th, (2001) on the statute of a European company (EC), which acquires the statute of a European joint-stock company and Council Directive 2001/86/EC of October 8th, (2001), which complements the statute of a European company with reference to participation of employees.
} 
security benefits to tourist companies which would accept the model program would probably be a matter of discussion. It seems reasonable to state that it would be more suitable if all countries made a prior decision about accepting proper solutions and regulations. Of course, it is not possible to envisage all circumstances of implementing participatory solutions and that is why one should expect that all the states which mutually shape the model solutions ought to declare a certain level of flexibility with regard to actions on the way to a broader implementation of schemes.

One should not expect quick and straightforward results concerning uniform legal frameworks and transnational programs because of i.a. a great number of various forms of financial participation, beginning from simple profit-sharing and share ownership through mixed solutions, yet in the case of a few most popular participatory forms, the model program could be a kind of basis and starting point for possible modifications, which seems indispensable while taking into account different regional and national conditionings. However, it is not possible to overcome all fundamental discrepancies between the member state, especially if these differences stem from completely dissimilar goals of national policies.

The role of all the social partners on the EU level should not be forgotten, ${ }^{5}$ and they should involve themselves more into the promotion and creation of transnational financial schemes, with active government support. So far, the present actions are not effective enough and they do not bring the expected results ${ }^{6}$ [comp. (van den Burg 2008)]. The efforts to design a European model of financial participation scheme has not succeeded so far, due to i.a. lack of readiness of some countries to take up such initiatives, rather more occasional than regular discussions on this topics and different targets of the state policy. In order to improve the above-mentioned situation it is necessary to provide more widespread education and a rise of awareness among the potential participants of financial schemes about the role of financial participation in the increase of tourist companies ' productivity $^{7}$ [comp. (Perotin and Robinson 2003)]. Many of the indicated solutions, after a closer analysis seem to be dependent on the two key steps: achieving the government support in the member states and achieving the institutional support, especially from the workers` organizations and potential, specially established promotion organizations. Such steps should play a significant role in the introduction of efficient financial participation schemes on o transnational level.

It seems that such international organizations as e.g. EFES, IAFEP (The International Association for the Economics of Participation), IAFP (The International Association for Financial Participation), ProEFP or NCEO (The National Center for Employee Ownership), in spite of their global meaning and position are not able to effectively promote

\footnotetext{
${ }^{5}$ On a EU level they are represented by three main organizations: European Trade Union Confederation (ETUC), which represents employees; UNICE-Union of Industrial and Employers`Confederations of Europe (currently known as Business Europe), which represents the private sector employers; European Centre of Enterprises with Public Participation and of Enterprises of General Economic Interest (CEEP), which represents the public sector employers.

6 The reader may find other opinions in this matter, as for example those presented by Ieke van den Burg, a member of the Economic and Monetary Affairs Committee in the European Parliament, who claims that the Parliament has been supporting any initiatives taken on a EU level in the field of promoting participation solutions for many years, but in practice, till 2018, almost nothing changed.

7 The authors stress that participation in profits, as well as share ownership "have bigger influence on productivity, when there is a good communication with the management and when employees can take part in managing the company and decision-making process".
} 
participation programs. ${ }^{8}$ This opinion may seem too critical, but is based on a still very small number of tourist companies applying such schemes.

It is difficult to recommend any radical actions which should be taken in order to improve the present situation, but maybe, which of course is debatable, it would be proper to start from (or continue) establishing a certain representative body, consisting of at least the representatives of the above-listed organizations, which in a way would consolidate actions of all entities dealing with promotion and implementation of financial participation programs. This organ could be of an advisory nature during the meetings of countries' representatives on a government level, in order to exert a more effective influence over the actions taken in this field by particular countries. Apart from this, this consolidating center could be obliged to spread information, monitor progress on legislative work in every state, conduct official studies and analyses of applied practices. Meetings of this committee (council) and social partners' representatives appear to be necessary to make the implementation of participatory solutions happen faster and more effectively.

It seems that so far social partners have not been devoting enough attention to the idea of financial participation, and at the same time they have played a vital role in educating their members and spreading information on this topic. Ever since it became rather obvious that the influence of financial participation on productivity and other economic aspects and workers' attitudes should be stronger when employees are informed and/or participate in business management, such actions have seemed to obligatory. Because of the above reasons, it is advisable to include in the agenda of social partners' meetings the matter of promoting financial participation not only in Europe.

Summing up the actions which needs to be taken in order to accelerate the diffusion of employee financial participation programs, the following aspects should be taken into consideration (European Economic and Social Committee 2010):

1. the application of participation schemes should be facilitated in the whole of the EU, on the basis of common regulations;

2. the growing quantity and variety of financial participation forms in recent years should by analyzed and the results of this study ought to be presented in a practical manner, in order to facilitate the use of financial participation, especially in small and medium tourist enterprises;

3. tourist companies which operate internationally should receive support in overcoming obstacles, mainly fiscal ones, in particular member states and the European Economic Area, so that participation could better serve as a means of strengthening employees' identification with the company and their sense of belonging;

4. it is necessary to devise such forms of participation which would increase the share of employees in company's results; it is advisable to create mechanisms allowing for transferability of competences from one country to the other (implementation of a mutual acknowledgement procedure between member states);

5. a positive attitude to participation, gained through employee's acquirement of ownership rights and the resulting sense of responsibility could contribute to strengthening the corporate governance in a company;

8 The number of companies with financial programs is growing rather slowly (Mathieu 2017). 
6. it is necessary to provide wider popularization of well-established financial participation solutions, and in this way contribute to their broader implementation; the EU should assign certain financial resources for this purpose;

7. financial participation programs are also a model of company's succession (employee buyout), which may guarantee further functioning and consequently competitiveness of European companies, and at the same time help them stay in the region;

8. the increase in remunerations and employees' spending power is way behind the productivity and incomes of stockholders; the consequences of the crisis on financial markets have got a negative impact on wage earners; depending on its form financial participation could - at least partially — compensate for the loss of spending power and be a factor leveling the market fluctuations, yet it should not be a substitute of payments' increases;

9. it is advisable to establish sources of information about the consequences of implementing programs for both tourist enterprises and employees, as well as developing services of independent institutions i.e. non-governmental organizations, related to training and counseling;

10. in cases where collectives agreements are a common practice, they should also be focused on the conditions of implementation of participation programs.

\section{A model of financial participation program in the European Union (proposal for tourism companies)}

The previous actions concentrated on overcoming the barriers taken by particular countries have turned out to be not effective enough. This encouraged the member states to devise a concept of model program of financial participation, which would be quite universal and applicable in most EU countries. The International Association for Financial Participation (IAFP) has become the project promoter in agreement with the European Commission. The model program of 2005 is based on the most important recommendations of the High Level Group of Experts on transnational barriers and presents a series of practices established on the grounds of financial participation principles included in the Communication of 2002 and included in the Report of the High Level Group of Experts in 2003 [comp. (Commission of the European Communities 2003)]. It was assumed that these recommendations will be used mainly by executive, employees and social partners during the discussion on the implementation of financial participation schemes in foreign subsidiaries. This refers to both large transnational enterprises as well small and medium tourist companies, which function on European markets or which are only on the point of starting their operation and want to implement a financial program for the first time.

The purpose of preparing a universal model was not only to provide a broader promotion and increase the number of companies using financial participation programs despite the boarders between them, as well as institutional, social and political barriers. The intention of the promotors was also to take actions which would facilitate the implementation and realization of financial participation schemes in particular countries and all required assistance in this field. Of course, there was and still is a certain danger that the universal principles of operating these programs may in the future become an obstacle on the way to a further diffusion of such solutions, but taking into account the international barriers and not fast enough spread of financial participation programs, it turned out necessary to take certain actions which would accelerate this process. The 


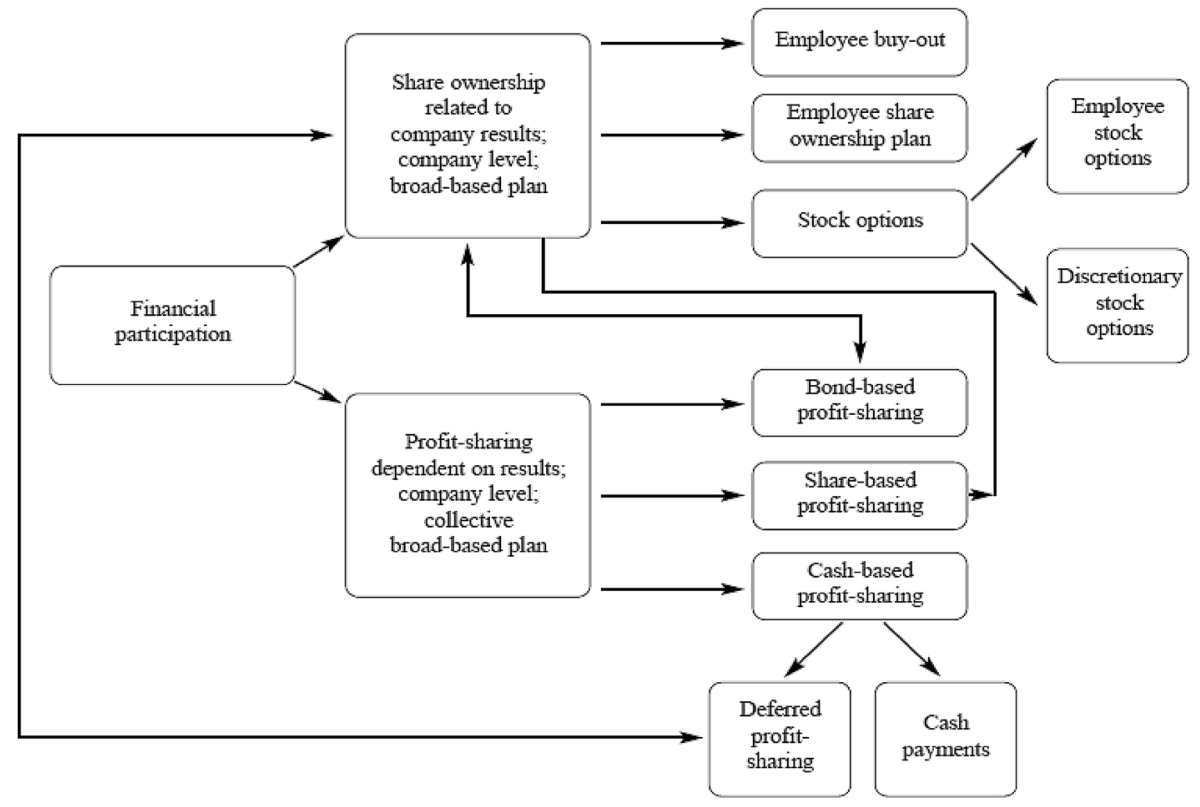

Fig. 1 Financial participation programs according to PEPPER. Source: Poutsma (2001)

originators tried to identify the areas which presented a problem for the implementation of schemes and on this basis adapt crucial, quite universal regulations, while at the same time leaving a certain dose of freedom with regard to the forms of introduces programs, facilitating in this way their application in particular countries. In their ranks there were representatives of 12 member states from social organizations, scholars, entrepreneurs, HRM advisors etc. A working version of the model programs was presented at a conference in Brussels in September 2005. It was attended by over 100 experts. Without imposing one specific program in particular countries, it seems that the universal solutions proposed by PEPPER (Promotion of Employee Participation in Profits and Enterprise Results) could be accepted (Fig. 1).

According to the PEPPER reports, these are financial participation programs mainly implemented on a company level and what is the most important they are broad-based. This means that there no significant limitations concerning the eligibility. It also means that programs which are developed outside the company and which relate to various forms of capital accumulation, e.g. on a regional or central level, are automatically excluded. This also implies that the more diffused and dispersed management-oriented schemes are set aside. Broad-based schemes for employees are implemented rather on a regular basis and subject to constant improvements, which proves a long-term aspect of this instrument. Such schemes can become an additional financial means used by tourist companies.

Programs should encompass participation of employees in company's profits or results and generate, apart from ordinary remuneration, additional payment. This means that there should be a specific formula which would link company's results to employees' benefits. Summing up, according to the European Commission, in the PEPPER programs focus ought to be put on these schemes which are introduced on a company level (applied within an enterprise), are broad-based (refer to a significant number of employees), are collective (available for all of employees), are regularly implemented and function in the long-run, 
providing workers with a share dependent on the effects achieved by a company (Uvalić 1991; O'Kelly and Pendleton 2005).

Participation of employees in the results obtained by a company has become an important matter for the EU, not only from the economic but also social point of view. It is perceived as a method to increase cooperation between the management, owners and employees, in order to reach common goals, reduce the number of conflicts in the workplace and achieve better effectiveness, productivity and other economic indicators.

The document contains a collection of regulations which were supposed to be a foundation for transnational financial participation programs taking into account particular legal, cultural, economic and other differences. The main forms of financial participation specified in the report, the most common ones, include voluntary participation of employees in ownership, as well as stock option plans. However, these are programs which are most difficult to implement on a transnational level because of the existing obstacles or impediments and because of their specificity. Therefore, it is necessary to refine and expand the model regulations in such a way which, despite this specificity, would allow for a relatively quick and trouble-free implementation of programs, including tourist ones.

However, in order to develop a transnational scheme of applicable participatory solutions, it was necessary to establish a working group of independent experts so as to identify analyze in detail the transnational barriers and find different ways to overcome them in particular countries. There was also a proposal to make use of a benchmark analysis to provide a better flow of information concerning the national policies and practices on the implementation of participatory solutions, as well as higher comparability of applied financial participation programs in the member states.

Apart from the barriers there were other problems such as i.a. a varying attitude to corporate governance in the member states of the costs of implementation of financial participation schemes, incurred by small and medium companies (including tourist ones). Particular obstacles required a great many methods and tools to liquidate them, bearing in mind the specificity of conditionings in separate states. One of such methods was to develop common benchmarking indicators in order to compare solutions concerning financial participation in the member countries. Efforts were made by the European Foundation for the Improvement of Living and Working Conditions and the IDEAS Institute (Dublin). As a result 16 indicators, covering three areas, had been devised (McCartney 2004):

(a) the level of use of financial participation;

(b) the nature of financial participation;

(c) the national policies and their characteristics, showing how the environment is shaped for the implementation of participation programs.

In the first area the key problem was to grasp the proportion between companies using financial participation programs and those which do not it. It was also vital to collect information on the quality of programs - whether they were broad-based, or maybe restricted to only specific groups of employees and whether employees wanted to join these schemes but could not, or maybe they did not want to participate at all.

With regard to the nature of financial participation attempts were made to establish general principles which would make a foundation for participatory systems, which at the same time would be in accordance with the realization of the Lisbon targets concerning growing competitiveness, pace of changes, social equality, uniformity etc. According to the will of the working team, the regulation should not be obligatory 
Table 1 Presentation of main fields of action requiring preparation of financial participation indicators. Source: McCartney (2004)

\begin{tabular}{|c|c|c|}
\hline Dimension & Topic & Subtopic \\
\hline \multirow[t]{2}{*}{ FP level } & 1. Availability & - \\
\hline & 2. Scope & - \\
\hline \multirow[t]{13}{*}{ FP nature } & 3. Voluntary participation & - \\
\hline & \multirow{2}{*}{$\begin{array}{l}\text { 4. Distribution of benefits to all employ- } \\
\text { ees }\end{array}$} & 1. Test for all employees \\
\hline & & 2. Testing similar conditions \\
\hline & \multirow[t]{4}{*}{ 5. Clarity and transparency } & 3. Employees' participation in FP \\
\hline & & 4. Providing trainings \\
\hline & & 5. Providing information \\
\hline & & 6. Evaluation mechanism \\
\hline & 6. Availability defined by formula & - \\
\hline & 7. Regularity & - \\
\hline & \multirow[t]{2}{*}{ 8. Avoiding irrational risk } & 7. Methods of payment \\
\hline & & 8. Minimum holding period \\
\hline & $\begin{array}{l}\text { 9. Differentiation between earnings, } \\
\text { salaries and incomes from FP }\end{array}$ & - \\
\hline & $\begin{array}{l}\text { 10. Compatibility with employees' } \\
\text { mobility }\end{array}$ & - \\
\hline \multirow{9}{*}{$\begin{array}{l}\text { National attitudes } \\
\text { and their charac- } \\
\text { teristics }\end{array}$} & \multirow[t]{2}{*}{ 11. Taxation } & 9. Taxation of FP \\
\hline & & 10. Social security contributions and FP \\
\hline & \multirow[t]{4}{*}{ 12. Cultural differences } & 11. History and tradition of FP \\
\hline & & 12. Other direct forms of participation \\
\hline & & 13. Citizen participation on stock markets \\
\hline & & 14. In-company trainings \\
\hline & \multirow[t]{3}{*}{ 13. Institutional differences } & $\begin{array}{l}\text { 15. Coordination of wage bargaining } \\
\text { system }\end{array}$ \\
\hline & & 16. Development of capital markets \\
\hline & & 17. Size of company \\
\hline
\end{tabular}

norms, and only recommendations suggesting a certain direction and coordination of the development of financial participation in the EU, while leaving enough space to maintain national traditions and individual needs of companies.

National policies and the involvement of the government in the creation of a friendly environment for the implementation of participatory solutions are the key element in favor of using financial participation. In this field a great number of differences have been identified between countries, which makes some of them more favorable and some less favorable to participation. Some of them which are worth mentioning may include the social and cultural climate (e.g. tendency to take a risk, knowledge of making investments, corporate culture), legislation and fiscal benefits supporting the implementation of participation or the experience in implementing schemes in the past. These factors may have a less direct impact on the introduction of programs, but this influence is vitally important. Of crucial role is here a fiscal policy (McCartney 2004).

These areas have been divided into topics and subtopics (Table 1) for which 39 indicators have been devised. 
With a ready list of topics and subtopics which should be included in a comparative analysis, the next step was to prepare specific ration and indicators, which would help to achieve a proper picture of financial participation in every member state. However, it must be noticed that the list presented in Table 1 does not seem to be complete by any means or it should be treated as a very general outline, which does not take into account the specificity of a particular country and the internal determinants, which may hinder the process of comparing different countries and make it less reliable. At the same time this analysis can be a good starting point for further studies and research because the changeability of environment requires them to be constantly conducted and the suggested theses must be verified. Without paying more attention to the methodology of the research, it ought to be stated that the indicators have been devised in a multilevel process. Most importantly, a list containing 39 operating indicators was prepared. The strategy was based on attributing at least one operating indicator to each of the topics or subtopics presented in Table 1. Next, these indicators were evaluated during a process of broad-based consultations. In certain cases it was necessary to add new indicators in order to fil in the gaps on the preliminary list or correct the existing ones, and also remove those which were found insignificant, bearing in mind the complexity and differentiation of financial participation forms.

The indicators were assigned to certain levels of importance by a group of experts so that it was possible to define their meaning for a given area. Such a method of measurement seems to be too subjective, but due to lack of other proposals the best one. A great many of the indicators suggest a significant differentiation of conditions influencing the shape of participatory solutions and also great difficulty with their harmonization on a transnational level. Thereby, these indicators and the general principles established by the European Commission may be a starting point for further actions aiming at the promotion and wider diffusion of financial participation programs in tourist industry. The actions undertaken by the EU should encourage enterprises to implement these schemes on condition that there will certain rules, legal norms and other regulations on the implementation of financial participation forms, but in the form of, maybe less popular, the aforementioned directives imposing in a way the necessity of operating employee financial schemes.

It has already been mentioned on many occasions that governments' and employers' organizations' interest should be aroused in these actions and they should also be convinced that these solutions are necessary and effective. As can be seen from different studies, there is a correlation of various forms of a broader involvement among employees with different forms of financial participation [comp. (Kalmi et al. 2004)]. A combination of different participatory practices may produce a synergy, and financial participation is even more effective when it is an element of interdependent policies aimed at employees' commitment, together with the presence of representatives and direct participation, based on clearly defined principles allowing for reaching these goals. The effects from a simultaneous implementation of several participatory forms are then much better. The proposed model takes into account these relationships.

Focusing their attention on the three major forms of financial participation (stock options is a third one, but in tourist companies rather difficult to implement), members of working teams have devised several additional principles, which should be taken into consideration by decision makers implementing participatory schemes (O'Kelly and Pendleton 2005):

1. Employees should be involved in the process of making key decisions concerning the project of a program, preferably through their representative bodies. It is assumed 
that a program functions properly only when employees also work on the project. The probability of achieving a success is much higher in this case.

2. It is necessary to establish a trustee, especially in the case of programs where benefits are deferred, in order to secure employees' interests in a better way.

3. Special regulations should be prepared which would allow for an evaluation of employees' share, in the case of non-listed companies.

4. Company's management is the supreme supervisor of a scheme and is obliged to take care of all participating employees.

5. The company should provide employees with necessary information on company's actions, financial results and achievements, before a given program is implemented, and in the following years such information should be given at least once a year.

6. In the event of special situations such as a merger, takeover or other restructuring actions, all participants ought to be informed about possible consequences of this situation to a further realization of a financial participation program.

7. At least once a year the representatives of company management should make an official statement on the value of shares in the hands of employees, methods of withdrawing dividends etc.

8. If possible, such information should be available online.

9. To make a program successful, it is necessary to lead a social dialog, that is why organizations which represent employees (trade unions and other representative bodies) should be involved in the planning process. If there are no such organizations, people responsible for developing a financial participation program ought to make efforts to engage employees in this process. It is also advisable to hold broad-based consultations.

10. Tourist companies should provide information on available programs in their native languages to avoid any misunderstandings and give access to important facts to those who do not know other languages.

11. The tourist company should organize courses and other forms of training for its employees concerning financial participation programs and their implementation. In certain situations such training courses may also be attended by social partners' organizations. These training sessions ought to be in accordance with the provisions of the national law and the regulations on financial and investment advisory services.

12. Allowances should be made for methods of communication with employees and providing them with information on the implementation and realization of financial program in which they participate, such as:

- a two-way flow of information during working hours;

- documentation which should, if possible, be sent to home and company address;

- regular internal bulletins (preferably issued quarterly) outlining significant achievements of the company and other vital information about the scheme;

- a telephone helpline providing answers to different inquiries, especially in the initial stage of running the scheme;

- making use of internal electronic forms of communication-intranet, email, memoranda etc.

It seems that the above provisions are necessary if a scheme is to function properly and it is supposed to cover as many employees as possible. It should be mentioned that has to 
be voluntary participation, and the company cannot force, or harass, those who refused to take part in a scheme. According the previously mentioned conclusions, programs should cover as many workers as possible, providing them with the same or similar conditions, which, however, may raise certain objections, e.g. on the part of employees with a longer job seniority who can be against including those who have only just started work. Implemented schemes ought to also be clear and transparent for all interested parties, and the procedures and rules of their functioning formulated in writing. One cannot forget that payments from financial participation programs should not depend on salaries and other forms remuneration included in the contract of employment. Profit-sharing or share ownership should be additions to, and not substitutes of ordinary salaries and wages. The same refers to the relationships between financial participation programs and other forms of savings in a company (e.g. pension funds). In this case, it is also necessary to clearly specify these correlations, or lack of them, and this information available to employees.

Another aspect is the risk concerning the implementation of financial participation programs, which means that employees should be aware of certain investment threats while purchasing or having shares of the company where they are employed. A potential risk resulting from the implementation of participation programs seems to be lowest in the case of cash-based payments from profits, where it may happen that resources will not be paid if a company encounters some problems. In general, this risk is more significant with reference to ownership programs which assume e.g. that stocks or shares may be frozen for a longer period before sale or in the case of pension plans, potential benefits should be expected in the long-run. Participating in employee ownership programs may be associated with a twofold risk. Firstly - a risk connected with a lack of diversification of the investment portfolio, and secondly - a risk of shares losing their value if the economic situation of a company gets worse. In the latter example employees might also lose their job.

A relationship between employees' commitment and value of shares of their company seems to be rather indirect and strongly determined by some external factors, and therefore workers are at risk of experiencing the influence of these external factors on the economic results achieved by their company. Another thread for participants of ownership schemes is posed by problems with selling shares and receiving money for them, especially in the case of non-listed companies (European Economic and Social Committee 2003).

An alternative to ownership programs may be savings schemes, where financial benefits obtained by employees are allocated in different funds, which partially spreads the risk. Cash-based payments from profits bear probably the lowest risk, which in general comes down to depreciation of money as a result of inflation, mainly in a situation when payments are significantly delayed in relation to obtained effects. Of course, the same effect will be visible if minimum holding periods are introduced to a program, and that is an obligatory withdrawal from cashing in shares or stocks. The longer the period when employees cannot make use of their bonuses, the more value they lose due to inflation. ${ }^{9}$ Summarizing the above deliberations, it is worth mentioning that implemented participation solutions offer substantial flexibility and employees should be given a chance to make their own choice of solutions available.

Another factor which may expose employees to risk of not receiving additional payments is the choice of indicators which influence profit volume, on the basis of which the

\footnotetext{
9 In some countries, e.g. France, in case of a statutory holding period, it is a common practice to compensate workers for losses resulting from inflation through different forms of indexation. This is a very good example of minimalizing a risk for employees.
} 
bonus is calculated. As a rule, bonuses from profit-sharing schemes are not directly linked with employees' commitment, and this results from the fact they are more often shaped by external factors e.g. the situation on global markets, political matters, raw materials' prices etc. than by efforts made on the part of particular employees or their groups. Consequently, participants of profit-sharing programs are at risk of not being given their bonuses due to certain unfavorable external conditions, even though they have worked very hard. This may lead the conclusion that programs based on gain-sharing, where bonuses are calculated in accordance with indicators of productivity, volume of customers' complaints etc., bear the lowest risk, on condition that bonuses depend directly on the results obtained by employees.

On these grounds, it can be stated that employees who join a financial scheme should have a chance to make a choice in order to minimalize the risk of not being granted the benefits due. This information ought to be made available to all workers before a given program begins its operation, so that they could be fully aware of a financial participation program they are going to decide on.

This potential risk stemming from financial participation should always be precisely defined and presented to all interested parties. Employees ought to be given a right to make decisions concerning every aspect of financial participation, which poses financial threats for them. Every aspect of this risk should be part of an informative and training strategy, and employees should have an opportunity to diversify potential dangers. This means that training courses should focus not only on the very fact of functioning of a given scheme, but also on how to manage a risk. However, this does not seem possible in all tourist companies introducing participatory solutions, yet it may determine the number of employees involved in this venture. The employee of course should be given enough time to consider his decision on joining a financial participation program.

Another factor which may be of crucial importance for a scheme to turn out to be successful is its final results. These effects, especially economic ones should have an active influence over the process of encouraging workers to join a given scheme and their later active participation in it. Employees' attitudes will be highly decisive of the final outcome. This is not an easy task, bearing in mind the previous, not always positive experience, especially in the context of manufacturing companies, where increased commitment of employees has not always produced desired effects. Nevertheless, a vision of future benefits, mainly financial ones, should incite workers to make greater efforts and take more actions, as well as joining financial programs. Therefore, is it necessary to state clearly whether shares in profits or granted stocks are the outcome of the results achieved by the whole company, team or individual employee. It seems unnecessary to go into the technical details of these matters, yet it must be remembered that this aspect is also very important if a program is to be successful. ${ }^{10}$

\footnotetext{
10 Information given to employees should refer to such matters as e.g. eligibility for shares or payments from profits in case of dismissals (e.g. regulations may state that all employee shares/stock options may be lost if certain conditions will not be met ("good versus bad leavers"), retirement (e.g. an obligation to repurchase shares by the employee in non-listed companies etc.); a minimum and maximum level of employee's contribution (employees' contributions should not exceed $10 \%$ of the annual income), granting periods (e.g. the granting period should be long enough to separate shares or bonuses from stock options from the current remuneration) and maturity periods; eligibility criteria for stock options; administering programs, minimum period allowing for participation in a scheme; methods of distributing shares; possibility of exchanging shares for cash; specifying in the regulations of a scheme what happens with employees' shares, which are in possession of a trustee or are not completely purchased, and a program is coming to an end because of a liquidation, merger or takeover; regularity of transfers of shares/part of profits intended for distribution; a list of duties and responsibilities on the part of the employer and the employee. This information may partly differ depending on the type of a program.
} 
The regulations and general provisions concerning financial participation programs functioning on a transnational level have been devised in order to overcome barriers and obstacles for their implementation. Identification of these impediments by all interested parties was necessary and at the same time helpful while developing a model program of financial participation. As can be seen, a significant number of barriers result from the specificity of a national legislation, so the project promoters tried to take this fact into account while formulating certain recommendations and presenting an approach based on well-established practices functioning in many companies in the European Union (i.a. in Italian tourist companies). As it appears, this model should not determine nether the choice of particular schemes nor the companies in which these schemes would be implemented. It should be possible to modify, improve, review and evaluate it because being familiar with the best available practices concerning financial participation within the European Union leads to development. The scheme is perceived as a core of the structure with the best practice, which may be extended by adding another elements. Particular companies may also choose an option to go beyond the regulations outlined in the model. One should hope that this model will be a useful frame of reference for tourist firms, social partners and governments, which means that it has to be broad-based and actively popularized as the most important source of reference for financial participation programs.

\section{Conclusions}

The empirical and theoretical aspects presented in this study are part of a broad spectrum of topics connected with financial participation in different kind of companies, including tourist ones. These issues still remain unsolved despite all the efforts made by different international research teams trying to grasp the relationships between many correlating factors related to various participation solutions used in enterprises. Both theory and practice require further steps in order to promote such solutions, which are unique in a way, and provide certain benefits while implemented. However, opinions of different authors on this subject vary, though a prevalent standpoint is that financial participation has got a positive impact on companies' results. Ambiguities among the results of research stem from many of the above-mentioned conditionings, which do make it easy to draw unquestionable conclusions. Nevertheless, it is assumed that benefits from the implementation of financial participation programs include: higher productivity, ${ }^{11}$ better communication, fiscal incentives (when applicable) ${ }^{12}$ [comp. (Oxera 2007)], providing employees with additional form of remuneration, reduced personnel turnover etc. It should also be mentioned that the positive effects of participation exert impact on organizational efficiency [comp. (Aoki 1990)]. The effects may be summarized in the following way ${ }^{13}$ :

\footnotetext{
11 Not everyone, however, supports this view. There are people who oppose the influence of financial participation on productivity, see Blanchflower and Oswald (1988).

12 It is difficult to say clearly whether fiscal incentives are the result variable from the implementation of a financial participation program, or maybe receiving tax reliefs persuades to apply the program. There are also opinions that programs without fiscal incentives are more profitable than those which have them.

13 These might be only illusory benefits and not necessarily the result of implementing a financial participation program because not all studies have confirmed this relationship (author's note).
} 
1. Participation might lead to making more wise decisions. Employees are often in possession of information which the management simply do not have. Additionally, participation allows for assuming different points of view, which, in turn, reduces the risk of "group unanimity".

2. Employees may be more willing to obey the decisions which they have helped to make and which are later imposed on them. Consequently, not only will they be aware of what is expected of them, but also of the fact that they have contributed to this process which leads to their obedience.

3. Motivation often rises owing to the establishment of goals in the participation decisionmaking process as well as through better rewarding for achieving certain results, which are employee-dependent.

4. Participation may improve communication and cooperation. Employees can "supervise" each other. Financial participation may also facilitate access to information about the organization through sharing one's experience and accelerate solving conflicts. In this case participation exerts influence over the so-called "dynamic efficiency" (Aoki 1990).

5. Financial participation contributes to better cooperation of regular workers and the management, increases effectiveness of handling problems as it reduces the amount of strife between them and improves relationships with their superiors.

These, of course, are not all the benefits stressed by proponent of researchers dealing with a range of problems connected wot participation, but it should be stated that employee ownership and financial participation programs may be a crucial contribution to the economic and social development of the EU. In general, they are favorable to employees, employers and the whole country as well. They offer workers benefits through providing a flexible and comprehensible remuneration program, which is based on rewarding employees' contribution to company's management and productivity. Financial participation, in case of combining with new forms of employee organizations, delivers benefits to the economies of member states due to a higher level of productivity and competitiveness in the era of globalization. Bearing in mind the Europe 2020 strategy, the implementation of employee financial participation may help European companies, especially SME, to improve their competitiveness owing to a stronger loyalty and attachment of qualified workers to their company, both through thick and thin. In this way employee financial participation makes it contribution to securing company's future existence. Part of company's profits are locally distributed among employees, which also increases the potential of the regional spending power. Financial participation of employees could also help to overcome the demographic problems because highly desired well-qualified employees will be offered with appealing working and living conditions. It is much easier to possess skilled staff in this way. Increased motivation through employee financial participation leads to higher work efficiency in a company and better company management. Employees' financial participation, depending on whether it is based on equity or outside resources, may raise the profitability of equity capital or the share of company's own capital. Consequently, this may facilitate access to outside capital and improve company's ratings.

The above opinions are expressed by a majority of researchers and authors of publications as well as those favoring the view that there is a general tendency to increase the level of financial participation, in spite of a large number of various schemes around the world (Poutsma 2001; Braam and Poutsma 2010). This tendency is also visible in service sector which is one of the most important part of the economy. European services are the backbone of European economic and social life, and since 2000 their role is growing and 
employment in the sector has risen (PROEFP 4). The service sector includes a vast range of activities that are part of what is called the Tertiary sector, including tourist companies. Financial participation in these companies is being linked to higher productivity and profits. ${ }^{14}$ Moreover, it seem that these effects are reinforced by the presence of other forms of employees' involvement. ${ }^{15}$ In order to promote financial participation it is necessary to overcome certain problems i.a. by means of providing proper legal frameworks, fiscal incentives and other financial benefits such as more flexible remuneration, making employees aware of a need for reducing costs, encouraging them to stay with the company, lowering risks on the part of the employer. The following may be listed:

1. Improved economic results of a company. Employee participation in general, and particular forms especially, may present a crucial premise to increase company's effectiveness and competitive edge over others on the market. For participation triggers entrepreneurship and creativity in employees, and generates innovative ideas etc. According to Japanese employers (Aoki 1983; Freeman and Weitzman 1987), who have gained a lot experience in this domain, employees hide unlimited possibilities inside themselves. It is only necessary to find a way how to make use of them. This may be achieved by means of certain forms of participation. In this way employees feel as if they were running their own business with all potential threads and consequences. Participation also creates a good environment for workers to help them reveal their organizational talents. Growing prospects of actions give an opportunity to take more advantage of one's knowledge and abilities, and predispositions as well. This makes it easier for the management to select the most gifted individuals and invest in their further development (trainings, postgraduate studies etc.).

2. Growing employees' commitment to their enterprise. Higher rights on the part of workers, which in general lead to their stronger influence over the decision-making process, are accompanied by taking more responsibility for what they have decided. Being more responsible for certain matters makes employees feel more attached to their firm, they try to perform their duties better and seize all the opportunities and possibilities that emerge. Consequently, they are also keen on company's matters after work and seek for solutions to occurring problems etc. Growing powers motivate workers to better performance, to stay with the company, even if there is a lucrative option to change jobs. Employees who are informed about the situation of their enterprise on a regular basis are more willing to offer a helping hand in times of crisis, to show more devotion for the good of the company (e.g. they agree to have their salaries temporarily reduced or resign from taking bonuses). Suitable forms of participation may turn out to be decisive for integrating employees' interest with those of the company. The authors' experience shows that such integrity might not even be guaranteed by high earnings.

3. Establishing partner-like relations in the company. Financial participation may develop partner-like relationships between employees and the management. Certain forms of participation generally lead to empowerment of employees in the workplace reorganizing the existing relations based on subordination to partner-like ones. Emergence of such a partner may turn out beneficial for the management as they may consult with him decisions to be made, seek advice on certain matters, engage him in solving particular problems etc. Partner-like relations are usually crucial for a favorable climate to appear in the workplace,

\footnotetext{
14 The role of profit-sharing is stressed by: Festing et al. (1999); share ownership as an instrument for increasing efficiency is highlighted by Blasi et al. (2003).

15 There are opposing arguments mentioned by other authors, which show a decrease in this commitment [comp. (Bryson and Freeman 2009)].
} 
avoiding protests or strikes when difficult problems have to be dealt with. Such relationships impose additional responsibility on the management and require stronger efforts. In fact, it is personal authority that determines the position of superiors, not the post they hold. The process of administering the company is transparent, which increases the management's responsibility even more.

4. Channeling employees' views. Channeling information is vitally important, especially when there are no trade unions in a company. Forms of financial participation may deliver effective means of communication between social partners. They are used to give signals about emerging issues just in the initial stage. Then there is enough time to explain them and solve everything. Executives will not be shocked when enormous problems are revealed out of the blue, and which are difficult or even impossible to resolve.

5. Presence of financial participation forms helps to implement new forms of work planning based on an extended autonomy. This refers mainly to the so-called team forms of work planning and the accompanying effect of synergy, which may be a vital source of company's success. Previous experience shows that it is easier to implement them when there are already other forms of participation in a firm and also solid relations between social partners, certain procedures for solving conflicts etc. Existence of such patterns increases employees' involvement in solving problems in their enterprise.

However, not all authors share these views about a positive impact of financial participation in companies. Those who are critical of financial participation claim that it may lead to many problems and conflicts in a company, and therefore lower company's efficiency. Such effects might be expected in all types of enterprises, including traditional ones with employees' minority share or in firms which apply participation solutions. Additional obstacles could emerge when workers' ownership share will be reinforced by participation in a decision-making process. On the list of general disadvantages one of the top places is occupied by the so-called "free-rider effect", where benefits are spread over a whole group of employees according to their efforts. Therefore, if each worker gets only a small part of additional income based on their individual work input, it might be expected that some of the employees will tend to shirk their duties; in this way another problem could occur related to monitoring the efficiency of individual workers. As a result, a drop in commitment and productivity may be expected, negatively correlated with the number of employees and additional costs spent on monitoring.

Employee financial participation programs are a research area for many environments and have been of great interest for economic empiricists for several years, yet with a various intensity of studies conducted. This tendency, as it may seems is rather on the increase, which unfortunately is not reflected by a high growth of companies implementing the aforementioned solutions. The tourist companies require even more attention.

A problem that needs to be solved relates to company succession in these companies. The European Commission draw attention to the fact that as a result aging European society one-third of the EU entrepreneurs, mainly owners of family-run businesses, will withdraw from the market during the next 10-20 years. This means that the process of transferring ownership rights will grow higher and it may cover several hundred thousand non-listed companies and a few millions jobs annually (Commission Communication to the Council 2006). Small and medium-sized companies are the biggest employers and a crucial element of the labor market policy. Therefore, a question arises whether it will be possible to maintain firms afflicted with this generational change and jobs which they provided. In a situation when more and more companies will have to face such a problem, a well-devised model of financial participation may be a way to guarantee succession in the form of selling part or the whole company to workers. This model may turn out effective 
in SME and family-run firms as an instrument allowing for their further functioning. ${ }^{16}$ The most suitable ones for guaranteeing company succession seem to be the ESOP models. A fundamental characteristic of the ESOP model is that it was specially developed for nonlisted companies. It encourages owners to give a company to employees instead of selling it to a third party and it also assumes that employees will gradually take over ownership in $100 \%$.

What fills with optimism is the initiative, enthusiasm and the actions taken in this area, yet without a more widespread and properly run promotional activities the implementation will take a long time. Studies which have been conducted on this subject are not only of a cognitive nature, but most of all they are of an applicable character, and their purpose is to provide a diagnosis of the existing mechanisms for the implementation of the abovementioned solutions and preparing recommendations useful for further popularization of financial programs in tourist companies and highlighting the actual benefits.

Open Access This article is distributed under the terms of the Creative Commons Attribution 4.0 International License (http://creativecommons.org/licenses/by/4.0/), which permits unrestricted use, distribution, and reproduction in any medium, provided you give appropriate credit to the original author(s) and the source, provide a link to the Creative Commons license, and indicate if changes were made.

\section{References}

Aoki, M.: Information, Incentives and Bargaining in the Japanese Economy. Cambridge University Press, Cambridge (1983)

Aoki, M.: Towards an economic model of the Japanese firm. J. Econ. Lit. 28, 1-27 (1990)

Blanchflower, D.G., Oswald, A.J.: Profit-related pay: prose discovered? Econ. J. 98(392), 720-730 (1988)

Blasi, J.R., Kruse, D.L., Bernstein, A.: In the Company of Owners. Basic Books, New York (2003)

Braam, G., Poutsma, E.: The influence of financial participation on company performance. Evidence from a Dutch Longitudinal Panel. Institute for Management Research. Nijmegen School of Management. Paper for the 15th World Congress of the International Association for the Economics of Participation (IAFEP), Université Panthéon-Assas, Paris II. 8-10 July (2010)

Bryson, A., Freeman, R.B.: Shared capitalism: does it work? p. 18, Centre Piece (2009)

Commission Communication to the Council, the European Parliament, the European Economic and Social Committee and the European Committee of the Regions, Implementing the Community Lisbon Program for Growth and Employment, p. 3, (COM(2006) 117 final). http://eur-lex.europa.eu/LexUriServ/ LexUriServ.do?Uri=COM:2006:0117:FIN:PL:PDF

Commission of the European Communities: Report of the High Level Group of independent experts, on cross-border obstacles to financial participation of employees for companies having a transnational dimension. European Commission, DG Employment and Social Affairs, Brussels (18 December 2003)

Council of the European Union: Council Regulation (EC) no. 2157/2001 and Council Directive no. 2001/86/ EC (8 October 2001)

European Economic and Social Committee: SOC/371, Employee financial participation in Europe, A. Graf von Schwerin (rap.), Draft Opinion of the Section for Employment, Social Affairs and Citizenship on Employee financial participation in Europe (own-initiative opinion). pp. 3-4, Brussels (2 September 2010)

European Economic and Social Committee, Opinion on the Communication from the Commission to the Council, the European Parliament, the Economic and Social Committee and the Committee of the Regions on a framework for the promotion of employee financial participation, p. 8, SOC/115, EESC, Brussels (2003)

Festing, M., Groening, Y., Kabst, R., Weber, W.: Financial participation in Europe-determinants and outcomes. Econ. Ind. Democr. 20(2), 295-329 (1999)

\footnotetext{
16 This aspect was already stressed by the Commission in recommendation 94/1069/WE on transferring ownership rights of small and medium companies, and then in a communication on transferring ownership rights of small and medium companies [comp. Opinion of the European... 2010].
} 
Freeman, R.B., Weitzman, M.L.: Bonuses and employment in Japan. J. Jpn. Int. Econ. 1(2), 168-194 (1987)

Kalmi, P., Pendleton, A., Poutsma, E.: The Relationship Between Financial Participation and Other Forms of Employee Participation: New Survey Evidence From Europe. Discussion paper no. 3, Helsinki School of Economics and HECER (April 2004)

Kostera, M.: Personnel Management, p. 31. PWE, Warsaw (1994)

Leleń, A.: Department of Work and Organizational Matters of CNBOP, Human Resources Management of the company. In Security and Fire Engineering, no. 18/2/2010, p. 2. CNBOP, Józefów (2010)

Mathieu, M.: Annual Economic Survey of Employee Share Ownership in European Countries 2016. European Federation of Employee Share Ownership, Brussels (2017)

McCartney, J.: Financial participation in the EU: Indicators for benchmarking, European Foundation for the Improvement of Living and Working Conditions, pp. 5, 18-20, 24, 45-46. Office for Official Publications of the European Communities, Luxembourg (2004)

Molenda, M.: Motivating as a tool for human resource management in a tourist enterprise. In: Rapacz, A. (ed.) Tourism Economy in the Region. Undertaking. Local government. Cooperation. Research Papers of Wrocław University of Economics, No. 379, p. 380. Publisher of University of Economics in Wroclaw, Wroclaw (2015)

O'Kelly, K.P., Pendleton, A.: Common Elements of an Adaptable Model Plan for Financial Participation in the European Union (draft), pp. 10-12, Brussels (September 2005)

Opinion of the European Economic and Social Committee on employee financial participation in Europe (own-initiative opinion), p. 7 (2010)

Oxera: Tax-advantaged Employee Share Schemes: Analysis of Productivity Effects, Report 2: Productivity Measured Using Gross Value Added. HM Revenue and Customs Research Report No. 33 (2007)

Perotin, V., Robinson, A.: Employee participation in profit and share ownership: a review of the issues and evidence. EN, European Parliament, Directorate General for Research, working paper, Social Affairs series SOCI 109 (2003)

Pocztowski, A.: Human Resources Management. Strategies-Processes-Methods, p. 36. PWE, Warsaw (2003)

Poutsma, E.: Recent Trends in Employee Financial Participation in the European Union, p. 19. European Foundation for the Improvement of Living and Working Conditions, Office for Official Publications of the European Communities, Luxembourg (2001)

PROEFP 4: Employee involvement in the postcrisis Europe benchmarking the commerce and service sectors. pp. 3, 7, 113, DG Employment, Social Affairs and Inclusion (VP/2015/003). http://www.proef p.eu/images/PROEFP/PROEFP4_Draft_Report.pdf

Uvalić, M.: Social Europe. The Pepper Report. Promotion of Employee Participation in Profits and Enterprise Results in the Member States of the European Community, p. 11. Florence and Brussels: Commission of the European Communities, Directorate General for Employment, Industrial Relations and Social Affairs, Supplement 3/91, Office for Official Publications of the European Communities, Luxembourg (1991)

Van den Burg, I.: Financial Participation and Employee Shareholding, Issues and Perspectives in Europe. p. 1 and the following. Eurofi 2008-Thursday 11/09/08 Session [4D], Nice (September 2008)

Publisher's Note Springer Nature remains neutral with regard to jurisdictional claims in published maps and institutional affiliations. 